\title{
Using modelling techniques to assess sewage pollution in the Potengi River Estuary, Brazil
}

\author{
C. de L. da N. Cunha ${ }^{1}$, A. C. Scudelari ${ }^{2}$ \& P. C. C. Rosman ${ }^{3}$ \\ ${ }^{1} U F P R$, Brazil \\ ${ }^{2} U F R N$, Brazil \\ ${ }^{3}$ COPPE/PEnO/UFRJ, Brazil
}

\begin{abstract}
The Potengi River Estuary (PRE) is a fragile system governed by the interaction of diverse physical-chemical and biological processes, and its ecological, economic and cultural importance for the State of Rio Grande do Norte, Brazil, is unquestionable. The present paper assesses sanitary sewage pollution in the PRE using a numerical model, thereby contributing to the solution of environmental problems. The water quality model used in this study is part of the Hydrodynamic Environmental System $\left(\right.$ SisBAHIA $\left.^{\circledR}\right)$. Organic matter is introduced into bodies of water mainly through the discharge of domestic sewage, although it may be present in industrial wastes or it may occur naturally, as part of biogeochemical cycles. Large amounts of organic matter may increase the number of microorganisms and, consequently, cause the excessive consumption of dissolved oxygen (DO). Two indicators of organic matter in water are generally used: biochemical oxygen demand (BOD) and dissolved oxygen (DO). Simulations were performed considering two scenarios: the current one and a projected one, which exhibits a 90\% removal of the BOD load. Results from the combined numerical model show that sewage discharged into the Baldo Channel reaches the estuary, accumulates along the regions nearest to it and significantly compromises water quality. However, the model shows that this improvement does not occur uniformly in the PRE.
\end{abstract}

Keywords: water quality model, Potengi River Estuary, environmental sanitation. 


\section{Introduction}

Coastal ecosystems and especially estuaries are vulnerable to the discharge of domestic sewage. The Potengi River Estuary (PRE) crosses the Metropolitan Region of Natal, an urban area with 1.4 million inhabitants [1], one of the most sought touristic destinations in the northeast region of Brazil and home to $43 \%$ of the State of Rio Grande do Norte population. Like any other tropical estuary, PRE constitutes an important natural breeding ground for mollusks, crustaceans and fish, and many shrimp farms have been established within the estuary as well. Due to industrial and urban development, the estuary has been subject to different environmental stresses, resulting in increased organic and industrial pollution.

In the last decade, Brazil has experienced the universalization of treated water supply. Currently, $99.4 \%$ of municipal districts have already been served [1] although, in average, only $78.6 \%$ of Brazilian residences have indoor plumbing, while in the northeast region; this rate drops to $68.3 \%$. In contrast to the improvement in water distribution, the percentage of municipal districts with sewage treatment is quite small: $28.5 \%$ in Brazil; $19.0 \%$ in the northeast region and $22.8 \%$ in Rio Grande do Norte state. According to the same census, only $44.0 \%$ of Brazilian residences are served by domestic sewage network, while in the northeast region this figure drops to $22.4 \%$ and, in Rio Grande do Norte state, to $17.4 \% .55 .2 \%$ of the population of Brazil, $45.7 \%$ of the northeast region and $35.3 \%$ of the State of Rio Grande do Norte population are covered by a sewage system. The percentage of municipal districts with sewage treatment is quite small: $28.5 \%$ in Brazil; $19.0 \%$ in the northeast region and $22.8 \%$ in Rio Grande do Norte state.

In the metropolitan region of Natal, there are practically no sewage treatment plants; only $35 \%$ of all the sewage produced is treated, and only $48 \%$ of this is properly disposed of [2]. Although, in general there is no direct measurement of the organic load from untreated domestic waste discharged into the water bodies in Brazil, and particularly into the PRE.

In this regard, hydrodynamic and water quality models developed to simulate long-term transport and evaluate sewage effluent pollution in estuaries are very useful tools as support to strategic decisions regarding urban planning, design of sewage outfalls, and coastal management. The present study aims to develop and to apply a numerical model to the PRE as a preliminary contribution to solving current environmental problems. Simulations were carried out to estimate spatial and temporal distribution of dissolved oxygen (DO), biochemical oxygen demand (BOD), salinity, temperature, and estuarine hydrodynamics.

The Hydrodynamic Environmental System known as SisBAHIA ${ }^{\circledR}$ (Base System of Environmental Hydrodynamics), developed by the Coastal and Oceanographic Engineering Sector of the Ocean Engineering Department at the Federal University of Rio de Janeiro (COPPE/UFRJ http: :|www.peno.coppe.ufrj.br/SisBahia). The system offers 2DH and 3D hydrodynamic model with constant density, a 2DH advective-diffusive Eulerian transport model, an advective-diffusive Lagrangian transport model and water 
quality models [3]. The water quality model assumes passive and nonconservative contaminant (i.e. the substances present in the water do not affect the hydrodynamic circulation of a body of water) and simulates the following water quality parameters: salinity, temperature, dissolved oxygen, Biochemical Oxygen Demand, Organic Nitrogen, Ammonia Nitrogen, Nitrate Nitrogen, Chlorophyll a, Organic Phosphorus and Inorganic Phosphorus. This model also allows the cycles to be resolved separately. In this case, the oxygen balance, nitrogen and phosphorous cycles can be resolved separately or together, in addition to temperature and salinity.

The DO-BOD module of SisBAHIA ${ }^{\circledR}$ was used to evaluate environmental pollution in the western portion of the PRE due to the capacity of these parameters to be used as dispersion indicators of other organic pollutants in the body of water. It also provides a balance between the forms of consumption and the sources of DO production because when consumption is higher than the source, DO concentration declines. The kinetic consumption processes and sources involved in the model for BOD are decay, oxidation, denitrification and deposition, and for DO are reaeration (source), growth or photosynthesis (source), respiration (consumption), nitrification (consumption), oxidation (consumption) and oxygen demand due to sediment (consumption).

The main area of interest within the PRE, regarding sanitary sewage pollution, is the Baldo Channel. Environmental pollution assessments were made for the current assumed untreated load and for future scenarios, with removal of $90 \%$ of the BOD load. In the simulation, DO concentration and BOD are used as indicators of the presence of organic matter in the natural water body and as parameters for evaluating the environmental pollution in PRE. Water temperature is significant because it influences all biological and chemical reactions in the water quality model. These simulations make it possible to evaluate the environmental impacts in the estuary caused by sewage effluent in its rivers, in order to study the best treatment solutions or devise specific monitoring levels.

\section{Description of the Potengi River Estuary (PRE)}

The PRE is located near the metropolitan area of Natal, at longitude $35^{\circ} 14^{\prime} \mathrm{W}$ longitude and $05^{\circ} 47^{\prime} \mathrm{S}$ latitude. The Potengi River basin covers an area of $4,307 \mathrm{~km}^{2}$ and it is the main hydrographic unit of Rio Grande do Norte state [4]. Nevertheless, due to the semi-arid climate of the northeast region of Brazil, fluvial contributions are intermittent and discharges are small, even during the rainy season, providing an insignificant fluvial contribution to the PRE. Figure 1 depicts the PRE, showing port of Natal and the watercourses that flow into the estuary, whose main tributaries are the Potengi River, the Jundiai River, the Doce River, the Baldo Channel. It is a shallow estuary, with depths mostly less than $4.0 \mathrm{~m}$, although in the main channel depths may reach $10.0 \mathrm{~m}$. Table 1 shows the average discharge of the rivers in the PRE basin [5]. 


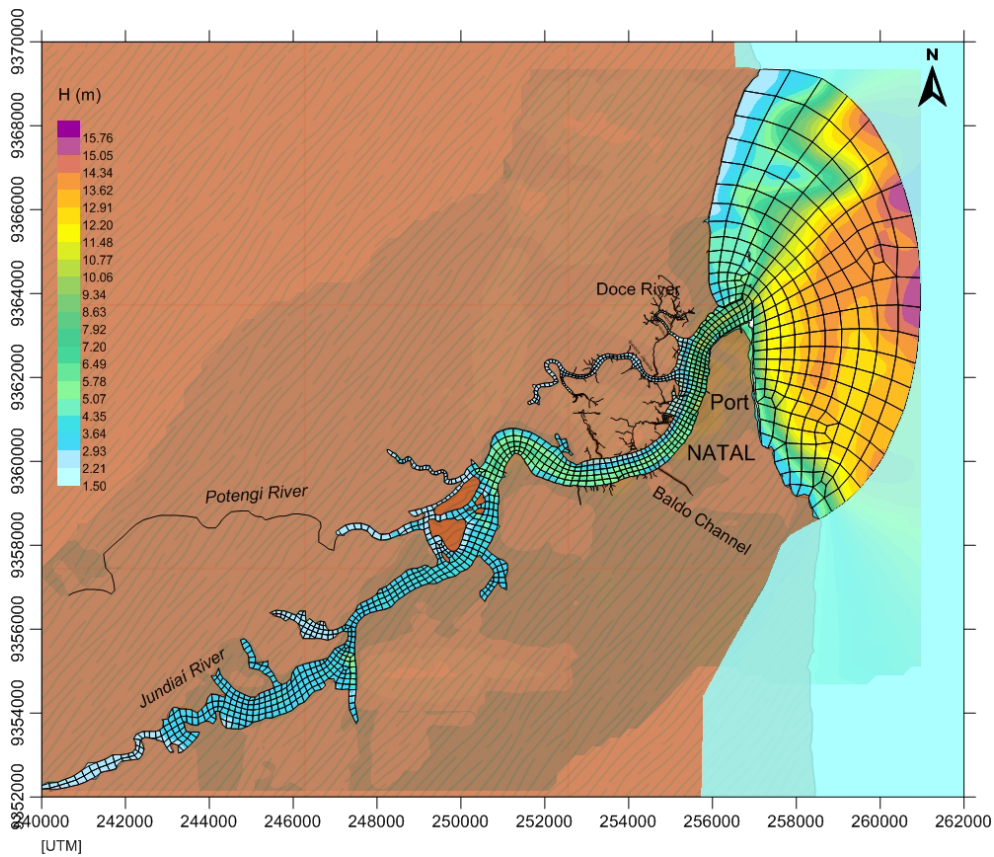

Figure 1: Modeling domain for the Potengi estuary system, showing the mesh with 1423 finite elements and 6774 nodes, the bathymetry as seen by the model and the principal rivers.

Table 1: Average discharge $\left(\mathrm{m}^{3} / \mathrm{s}\right)$, DO $\left(\mathrm{mg} \mathrm{O}_{2} / \mathrm{L}\right)$, BOD $\left(\mathrm{mg} \mathrm{O}_{2} / \mathrm{L}\right)$, temperature $\left({ }^{\circ} \mathrm{c}\right)$ and salinity (psu) values in the rivers used in the simulation.

\begin{tabular}{|c|c|c|c|c|c|}
\hline River & Discharge & $\begin{array}{c}\text { DO } \\
(\mathrm{mg} / \mathrm{L})\end{array}$ & $\begin{array}{c}\text { BOD } \\
(\mathrm{mg} / \mathrm{L})\end{array}$ & $\begin{array}{c}\text { Temp. } \\
\left({ }^{\circ} \mathrm{C}\right)\end{array}$ & $\begin{array}{c}\text { Sal. } \\
(\mathrm{psu})\end{array}$ \\
\hline \multicolumn{6}{|c|}{ Scenario 1} \\
\hline Potengi & 5.0 & 5.0 & 10.0 & 22.0 & 0.5 \\
\hline Jundiai & 5.0 & 5.0 & 10.0 & 22.0 & 0.5 \\
\hline Doce & 2.0 & 5.0 & 10.0 & 22.0 & 0.5 \\
\hline Baldo Channel & 0.8 & 0.0 & 300.0 & 22.0 & 0.5 \\
\hline \multicolumn{6}{|c|}{ Scenario 2} \\
\hline Potengi & 5.0 & 5.0 & 10.0 & 22.0 & 0.5 \\
\hline Jundiaí & 5.0 & 5.0 & 10.0 & 22.0 & 0.5 \\
\hline Doce & 2.0 & 5.0 & 10.0 & 22.0 & 0.5 \\
\hline Baldo Channel & 0.8 & 0.0 & 30.0 & 22.0 & 0.5 \\
\hline
\end{tabular}

Three sources of pollution are present in the PRE: shrimp farm effluents organic pollution from industrial origin, and domestic waste effluents. Since there is no quantitative data from shrimp pond effluents and the industrial 
contribution is not relevant, this study will focus on the organic pollution from domestic waste alone. Because there are no direct measurements of the organic loads released into the PRE, it will be assumed an average BOD concentration equal to $300 \mathrm{mg} / \mathrm{L}$, a value frequently adopted as typical for sanitary sewage in Brazil [6].

\section{Hydrodynamic circulation in PRE}

The correct characterization of hydrodynamic circulation in the PRE is the first step in the study of passive scalar dispersion in the estuary. If the horizontal scales are at least two orders of magnitude larger than those of the vertical scales, if the discharge of interest is predominantly horizontal, and if very weak stratification patterns are observed, the velocity of currents can be well represented by mean variables in the vertical dimension. In these cases, the vertically averaged governing equations can be applied, thus eliminating the vertical dimension of the problem. In the PRE, the medium depth of the channel is equal to $5.0 \mathrm{~m}$ and the width is equal to $500.0 \mathrm{~m}$; consequently, it is possible to use the two-dimensional models.

The present study uses a two-dimensional hydrodynamic model (2DH) to characterize the hydrodynamic circulation in the PRE. The numerical domain is shown in Figure 1, where the mesh of sub-parametric Lagrangian finite elements consists of 9-node quadrilaterals, totalling 1423 elements and 6774 nodes. The time step is $30 \mathrm{~s}$.

Simulation of the hydrodynamic circulation pattern considered only one (astronomical) tidal cycle between May 11 and May 12 2003. Considering the extreme complexity of the hydrodynamic circulation of the Potengi River Estuary and focusing attention on the main phenomena that influence circulation, assuming that the circulation of interest is due to long-term forces resulting from interactions between tides and winds, the most adequate model for characterizing hydrodynamic circulation can be defined. Tide ranges run from $2.83 \mathrm{~m}$ during spring tides and $1.33 \mathrm{~m}$ during neap tides. Tides in the PRE are semidiurnal with diurnal inequalities and a set of 24 main harmonic constants, with M2 (amplitude: $80.9 \mathrm{~cm}$ ) and S2 (amplitude: $27.9 \mathrm{~cm}$ ) as their main components.

Hourly values of wind velocity measured at the Automatic Surface Meteorological Station, near the PRE, uniformly distributed over the entered numerical domain were used as input. River discharges were also taken into account [4]. The adopted average river discharge values are given in Table 1. At all land boundary nodes, the tangential velocity component is zero. The bottom friction coefficient is expressed in terms of the Chézy coefficient, which depends on the amplitude of the equivalent bottom roughness. The latter, in turn, was based on the characterization and distribution of bottom sediment. Sand is predominant in the main channel (approximately $0.030 \mathrm{~m}$ ), whereas sandbanks predominate near the island and near the port of Natal. 


\section{Calibration of the hydrodynamic model}

Results of the hydrodynamic circulation model in the PRE were compared to measured current velocities and total water depth at Station E (Figure 2). The model was run from May 11 to May 12 2003, using the predicted tides presented in Figure 3. The imposition of the tide curve is done along the open boundaries of the domain modelled.

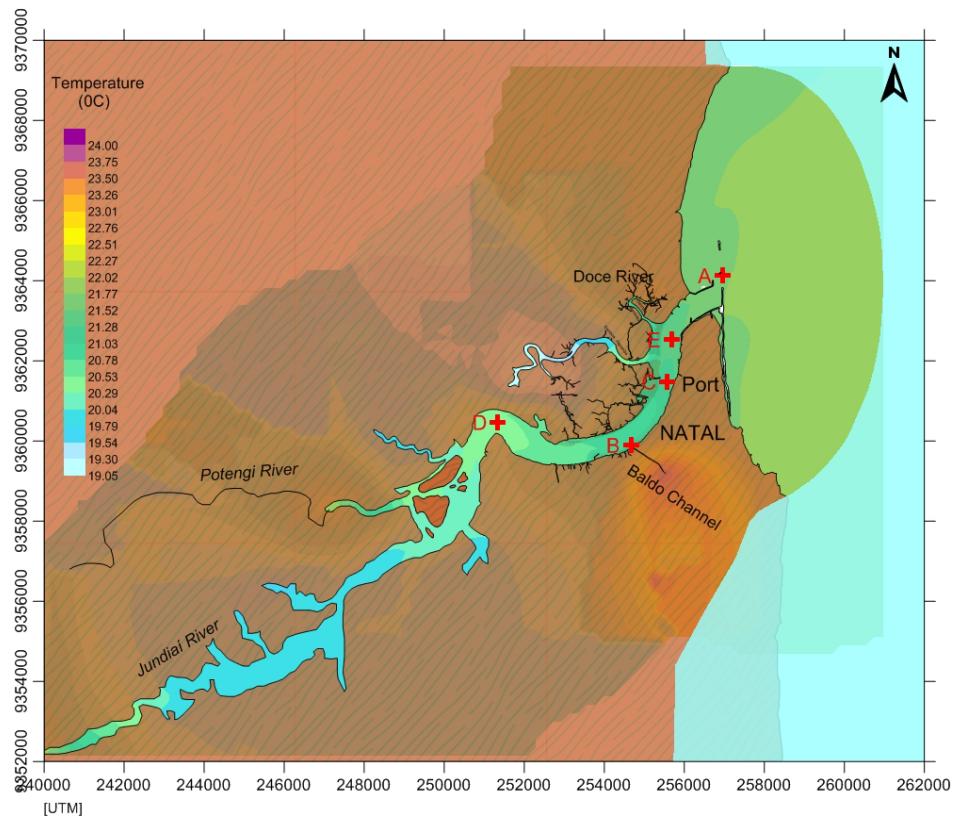

Figure 2: Spatial distribution of temperature and location of the water quality (stations A, B, C and D) and current stations (station E) from which measured data were used to compare with numeric results.

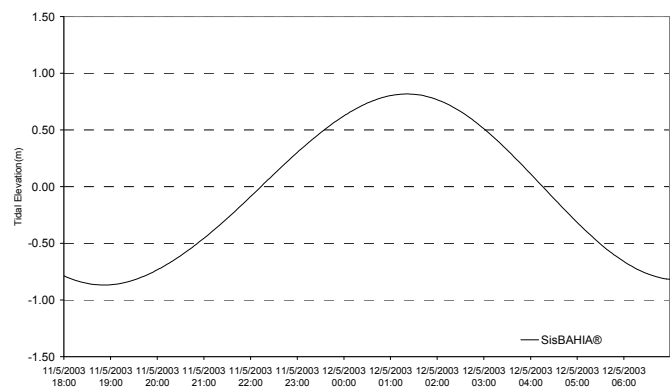

Figure 3: Tidal elevation at the port of Natal from 11 to 12 May 2003. 
Figures 4, 5 and 6 illustrate the time series of water depth, east-west and north-south components of the current for station E. Even considering such a short time span of only one tidal cycle, a good agreement between the computed and measured water depth, both in phase and in amplitude, was achieved (Figure 4). Because station $E$ is located at the entrance of the narrow main channel, where bathymetry is very irregular, the current velocities exhibit a wide spatial variation. The computed E-W velocity components (Figure 6) show good agreement with the measured values. A small amplitude difference can be observed at the beginning of the series. However, the results obtained for the N$\mathrm{S}$ velocity components (Figure 5) do not display good agreement with those measured.

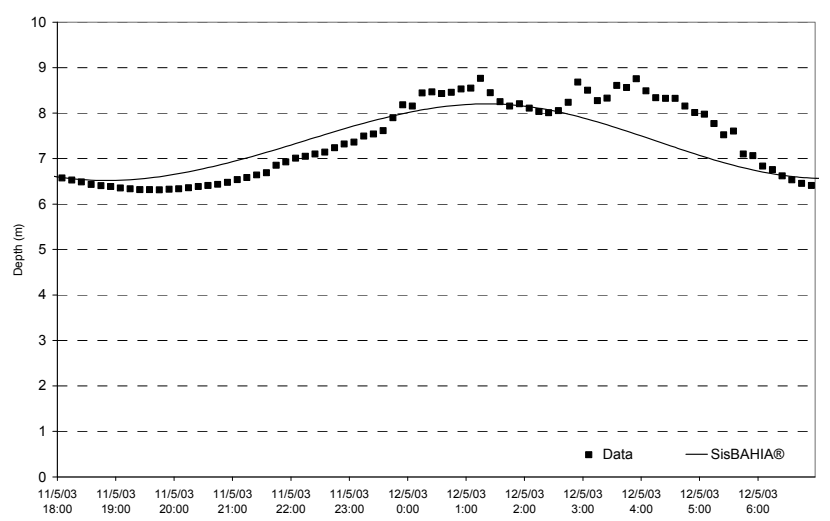

Figure 4: Depth measured at station $\mathrm{E}$ and computed numerically (SisBAHIA $^{\circledR}$ ) from 11 to 12 May 2003.

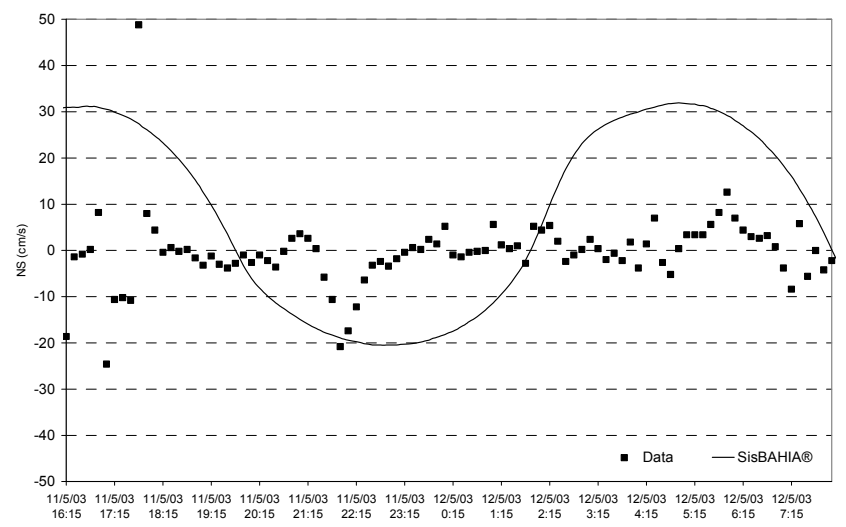

Figure 5: North-south component of the current measured at station $\mathrm{E}$ and computed numerically (SisBAHIA ${ }^{\circledR}$ ) from May 11 to 122003. 


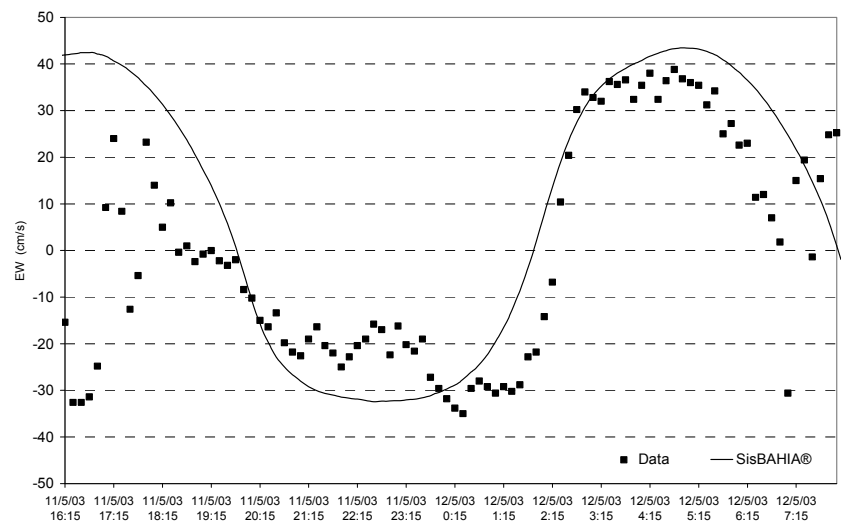

Figure 6: East-west component of the current measured at station $\mathrm{E}$ and computed numerically (SisBAHIA®) from May 11 to 122003.

Based on these results, the tidal current in the Potengi estuary exhibits a peak flood current of $0.42 \mathrm{~m} / \mathrm{s}$, and maximum ebb speed of $0.32 \mathrm{~m} / \mathrm{s}$ at station E. The shallow water effect is considerable in current variations, accounting for symmetries in ebb-flood current distribution.

\section{Water quality model in PRE}

The main objective of this paper is to develop a water quality model to assess sewage effluent pollution in the PRE, characterizing Dissolved Oxygen (DO) and Biochemical Oxygen Demand (BOD).

After the runs of the hydrodynamic model described in the previous section, a new set of simulations was conducted for the entire year of 2010, considering the predicted tide and the wind measurements for that year. All other input parameters of the hydrodynamic model were maintained. Water quality simulations were conducted for the current conditions (scenario 1) and for a future situation (scenario 2), assuming an improvement in sewage treatment with a $90 \%$ removal of BOD load. Table 1 shows BOD and DO concentrations, as well as temperature and salinity values in the rivers used for boundary conditions in the two simulations [7].

The water quality model developed applies the same spatial grid as the hydrodynamic model (note that a different time step length can be employed in the analyses). Flow velocities and turbulence coefficients, already computed by the hydrodynamic model, can be directly used by the water quality model.

The initial conditions are spatially homogeneous and equal for the two scenarios: salinity $(0.05 \mathrm{psu})$, temperature $\left(21.0^{\circ} \mathrm{C}\right)$, BOD $(2.0 \mathrm{mg} \mathrm{O} / \mathrm{L})$, and DO $\left(7.0 \mathrm{mg} \mathrm{O}_{2} / \mathrm{L}\right)$. A permanent concentration in the entire modelled domain was considered, as follows: ammonia nitrogen $(0.4 \mathrm{mg} \mathrm{N} / \mathrm{L})$, nitrate nitrogen $(0.4$ $\mathrm{mg} \mathrm{N} / \mathrm{L})$, and chlorophyll a $(0.05 \mu \mathrm{g} / \mathrm{L})$. The model coefficients and constants employed in the numerical simulation are presented in Table 2 [8]. 
Table 2: Constants of the water quality model used by SisBAHIA ${ }^{\circledR}$ for the PRE model.

\begin{tabular}{|l|c|c|}
\hline Description & Units & Constant \\
\hline Algal biomass death rate & day $^{-1}$ & 0.02 \\
\hline De-oxygenation rate at $20^{\circ} \mathrm{C}$ & day $^{-1}$ & 0.05 \\
\hline Half-saturation constant for oxidation of BOD & $\mathrm{mg} \mathrm{O}_{2} / \mathrm{L}$ & 0.50 \\
\hline Organic matter settling velocity & $\mathrm{m} /$ day & 0.00 \\
\hline Fraction of dissolved BOD in the water column & & 0.50 \\
\hline Denitrification rate at $20^{\circ} \mathrm{C}$ & day $^{-1}$ & 0.09 \\
\hline $\begin{array}{l}\text { Half-saturation constant for DO limitation in } \\
\text { the denitrification process }\end{array}$ & $\mathrm{mg} \mathrm{N}^{-\mathrm{L}}$ & 0.10 \\
\hline Re-aeration rate at $20^{\circ} \mathrm{C}$ & day $^{-1}$ & 1.38 \\
\hline Nitrification rate at $20^{\circ} \mathrm{C}$ & day $^{-1}$ & 0.02 \\
\hline $\begin{array}{l}\text { Half-saturation constant for DO limitation in } \\
\text { the nitrification process }\end{array}$ & $\mathrm{mg} \mathrm{O}_{2} / \mathrm{L}$ & 0.30 \\
\hline Algal biomass growth rate & day $^{-1}$ & 0.30 \\
\hline Algal biomass respiration rate at $20^{\circ} \mathrm{C}$ & day $^{-1}$ & 0.12 \\
\hline
\end{tabular}

Spatial distribution of temperature is presented in Figure 2, whereas Figure 7 shows the spatial distribution of salinity in PRE. The average water temperature is around $21^{\circ} \mathrm{C}$, with a little thermal horizontal stratification. In the outer area, salinity is close to $25.0 \mathrm{psu}$, the boundary condition established for the open ocean boundary. Inside the estuary, a hard horizontal gradient of salinity is observed, because of the boundary condition imposed on the rivers (Table 1). Low salinity values are recorded in the innermost area of the estuary (Figure 7). In the region between the port of Natal and the Baldo Channel, an area of intense mixture is formed, favoring the dispersal of sanitary sewage into the Baldo Channel.

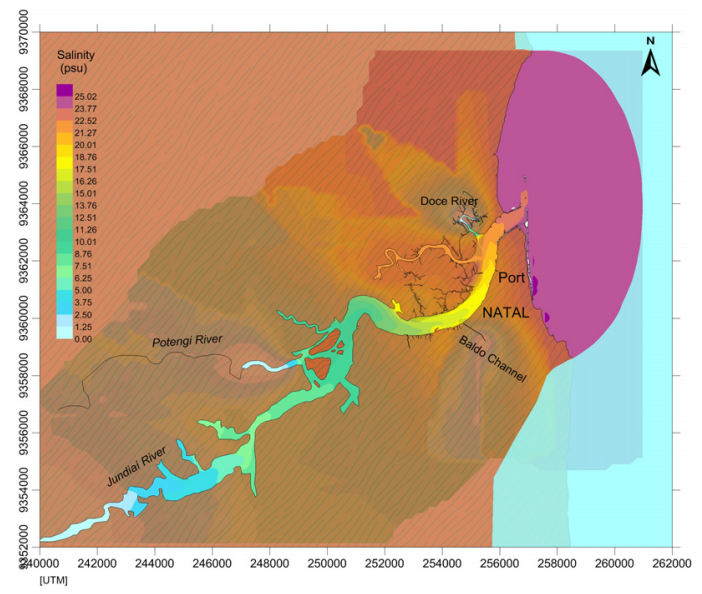

Figure 7: Spatial distribution of salinity in PRE. 
Figure 8 shows BOD concentrations obtained by SisBAHIA $^{\circledR}$ for four stations, considering scenarios 1 and 2. Oscillatory behavior can be observed, as well as a large dispersion of the results around the median values. Station A, located in the external region of the estuary, shows that variations in BOD concentrations are small and similar between the two load scenarios, demonstrating that the coastal area is little affected by the release of sanitary sewage inside the estuary. Station B, near the Baldo Channel, exhibits a wide variation in BOD concentration considering scenario 1, for the current load. In the scenario involving 90\% BOD removal, concentrations are significantly reduced. Stations C and D display similar behavior and values for BOD concentrations.
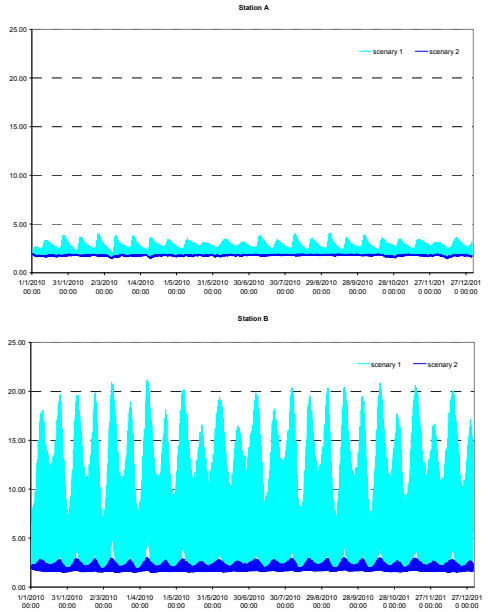
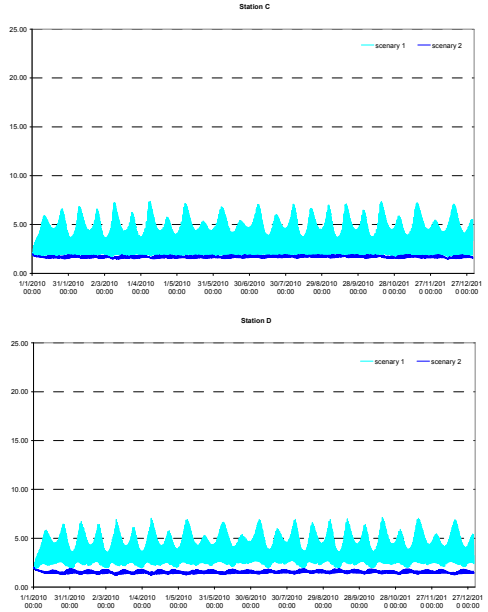

Figure 8: $\quad$ BOD concentrations obtained by $\operatorname{SisBAHIA}^{\circledR}$ at stations $\mathbf{A}$, in the external area; $\mathbf{B}$, near the Baldo Channel; $\mathbf{C}$, near the port of Natal; and $\mathbf{D}$, in the internal area of the estuary, considering scenarios 1 and 2.

The reduction observed in scenario 2 does not occur uniformly at all the monitoring stations, indicating that the results of the water quality model can be used qualitatively; that is, they allow different scenarios to be compared even if the model has not been fully calibrated. It is also clear that if long term monitoring data had been available to calibrate the model, this tool could have been used to provide more secure quantitative information, thus contributing to the multiple management of this body of water.

The DO concentrations obtained by SisBAHIA $^{\circledR}$ for the four stations, considering scenarios 1 and 2, are shown in Figure 9. It must be noted that the DO concentration values for stations $\mathrm{A}, \mathrm{C}$ and D are high and always greater than $7.0 \mathrm{mg} \mathrm{O}_{2} / \mathrm{L}$. The lowest $\mathrm{DO}$ values are found at the station near the Baldo Channel (station B). Brazilian environmental laws [9] establish the usage of water bodies according to water quality criteria based on concentrations of DO, 
BOD, temperature and other parameters. These values distinguish the water (or the water body) as appropriate for recreation at primary contact, protection of aquatic fauna and natural and/or intensive breeding of specimens, and for human consumption.
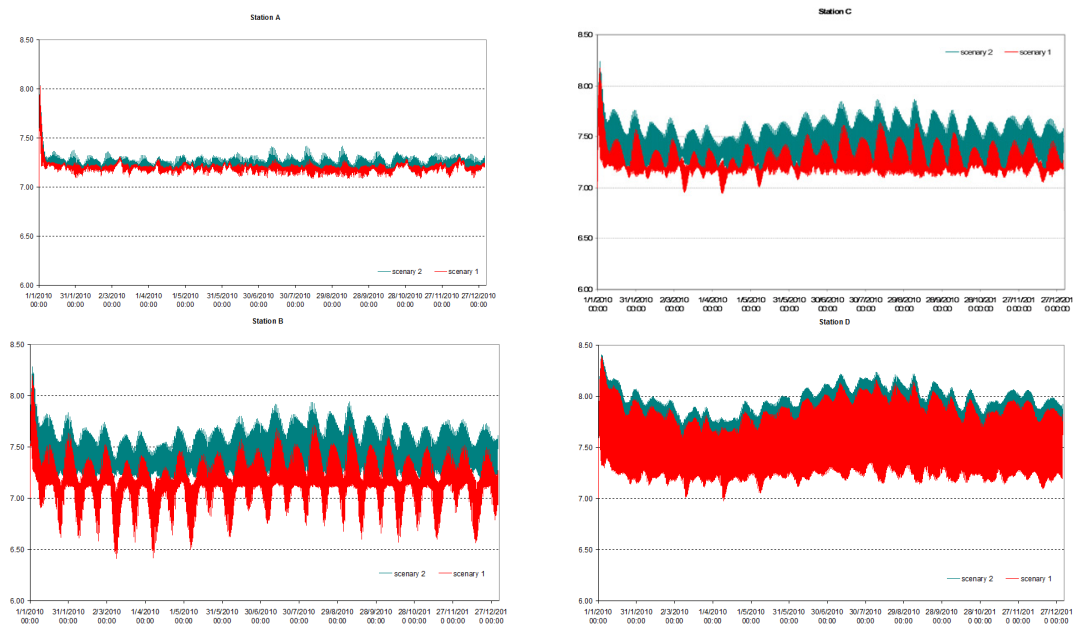

Figure 9: DO concentrations obtained by $\operatorname{SisBAHIA}^{\circledR}$ at stations $\mathrm{A}$, in the external area; B, near the Baldo Channel; $\mathrm{C}$, near the port of Natal; and $\mathrm{D}$, in the internal area of the estuary, considering scenarios 1 and 2.

\section{Conclusions}

Water quality in the Potengi River Estuary (PRE) was examined using a combined hydrodynamic and water quality model to evaluate sewage effluent pollution. The combined model used SisBAHIA ${ }^{\circledR}$, finite elements and finite differences, for spatial and time discretization. Mean salinity in the PRE is generally around $12 \mathrm{psu}$, with variations only at the estuaries of the main rivers. Mean water temperature is $21^{\circ} \mathrm{C}$, and mean DO concentration $7.5 \mathrm{mg} \mathrm{O} / \mathrm{L}$. Although a longer time series of data is needed for adequate model calibration, some important conclusions may still be drawn as well as an indication of adequate locations for future data collection. In the simulation, DO and BOD were used as indicators of the presence of organic matter in the water body and as parameters for evaluating environmental pollution in the Potengi River Estuary. Simulations were performed considering two scenarios: the current conditions and a projected one with $90 \%$ removal of BOD load. Results from the combined numerical model show that sewage discharged into the Baldo Channel reaches the estuary, accumulates in areas nearest to the estuary and significantly compromises water quality. For scenario 2, conditions are better, mainly in the region near the Baldo Channel. It seems reasonable that an improvement can be 
observed if a $90 \%$ load reduction is achieved. However, the model shows that this improvement does not occur uniformly in the PRE.

\section{References}

[1] IBGE, www.ibge.gov.br/home/estatistica/populacao

[2] Araújo, A. G. de., Avaliação da poluição por metais pesados no estuário do rio Potengi - Natal/RN. Brazil: Universidade Federal do Rio Grande do Norte, Master's thesis, p. 92 (in Portuguese), 2005.

[3] Rosman, P. C. C., Referência Técnica do SISBAHIA. COPPE: Rio de Janeiro, Brasil. (in Portuguese), online: www.sisbahia.coppe.ufrj.br

[4] SERHID, www.serhid.rn.gov.br/consulta/cBacia.asp

[5] Cunha, E. M. S. Evolución actual del litoral de Natal - RN (Brasil) y sus aplicaciones a la gestión integrada. Spain: University of Barcelona. Ph.D. thesis, p. 384, 2004.

[6] Campos, H. M. \& Sperling, M. von. Estimation of domestic wastewater characteristics in a developing country based on socio-economic variables. Water Science and Technology, 34, pp. 71-77, 1996.

[7] Cunha, C. L. N., Scudelari, A. C., Gonçalves, J. E. and Mercuri, E. G. F. Assessment of sanitary sewage pollution in the Paranaguá estuarine complex of Paranaguá, Brazil using environmental modeling. Journal of Coastal Research, 64, pp. 912-916, 2011.

[8] Cunha, C.; Rosman, P.; Ferreira, A. P.; Monteiro, T. Hydrodynamics and water quality models applied to Sepetiba Bay. Continental Shelf Research, 26, pp. 1940-1953, 2006.

[9] CONAMA (Conselho Nacional de Meio Ambiente - National Environment Council), RESOLUTION No 357, Published 18/03/2005, pp. 58-63. (in Portuguese). 